\title{
Safety assessment during initiation and maintenance of propranolol therapy for infantile hemangiomas
}

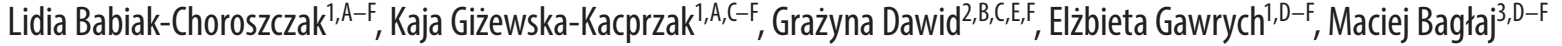 \\ ${ }^{1}$ Department of Pediatric and Oncological Surgery, Urology and Hand Surgery, Pomeranian Medical University, Szczecin, Poland \\ ${ }^{2}$ Department of Pediatrics, Endocrinology, Diabetology, Metabolic Diseases and Cardiology of Developmental Age, Pomeranian Medical University, Szczecin, Poland \\ ${ }^{3}$ Department of Pediatric Surgery and Urology, Wroclaw Medical University, Poland \\ A - research concept and design; $\mathrm{B}$ - collection and/or assembly of data; $\mathrm{C}$ - data analysis and interpretation; \\ $D$ - writing the article; $E$ - critical revision of the article; $F$ - final approval of the article
}

\section{Address for correspondence}

Kaja Giżewska-Kacprzak

E-mail:k.gizewska@gmail.com

\section{Funding sources}

None declared

Conflict of interest

None declared

Received on July 4, 2018

Reviewed on July 26, 2018

Accepted on August 9, 2018

Published online on January 15, 2019

Cite as

Babiak-Choroszczak L, Giżewska-Kacprzak K, Dawid G, Gawrych E, Bagłaj M. Safety assessment during initiation and maintenance of propranolol therapy for infantile hemangiomas. Adv Clin Exp Med. 2019;28(3):375-384. doi:10.17219/acem/94136

DOI

10.17219/acem/94136

Copyright

Copyright by Author(s)

This is an article distributed under the terms of the

Creative Commons Attribution Non-Commercial License

(http://creativecommons.org/licenses/by-nc-nd/4.0/)

\begin{abstract}
Background. Propranolol is an effective method of treatment for infantile hemangiomas (IH). A recent concern is a shift of the therapy into outpatient settings.

Objectives. The aim of the study was to evaluate the safety of initiating and maintaining propranolol therapy for $\mathrm{HH}$.

Material and methods. The study involved 55 consecutive children with $1 \mathrm{H}$ being treated with propranolol. The patients were assessed in the hospital at the initiation of the therapy and later in outpatient settings during and after the therapy. Each time, the following monitoring methods were used: physical examination, cardiac ultrasound (ECHO), electrocardiography (ECG), blood pressure (BP), heart rate (HR), and biochemical parameters: blood count, blood glucose, aspartate transaminase (AST), alanine transaminase (ALT), and ionogram. The therapeutic dose of propranolol was $2.0 \mathrm{mg} / \mathrm{kg} /$ day divided into 2 doses.
\end{abstract}

Results. Four children were excluded during the qualification or the initiation of propranolol; a total of 51 patients were subject to the final analysis. All the children presented clinical improvement. There was a significant reduction in the mean HR values only at the initiation of propranolol. There were no changes in HR during the course of the therapy. Blood pressure values were within normal limits. Both systolic and diastolic values decreased in the first 3 months. Bradycardia and hypotension were observed sporadically, and they were asymptomatic. Electrocardiography did not show significant deviations. The pathological findings of the ECHO scans were not a contraindication to continuing the therapy. There were no changes in biochemical parameters. Apart from 1 symptomatic case of hypoglycemia, other low glucose episodes were asymptomatic and sporadic. The observed adverse effects were mild and the propranolol dose had to be adjusted in only 6 cases.

Conclusions. Propranolol is effective, safe and well-tolerated by children with $\mathbb{H}$. The positive results of the safety assessment support the strategy of initiating propranolol in outpatient settings. Future studies are needed to assess the benefits of the therapy in ambulatory conditions.

Key words: infantile hemangioma, propranolol, ECG monitoring, blood pressure, adverse effects 
Infantile hemangiomas $(\mathrm{IH})$ are the most common benign tumors of infancy, affecting about $10-12 \%$ of infants, including $20-30 \%$ of babies born prematurely. ${ }^{1}$ Their natural development includes a phase of intensive growth (proliferation) lasting up to 18 months of age and a phase of slow disappearance (involution). In $40 \%$ of children, the $\mathrm{IH}$ does not leave traces or minimal residues. ${ }^{2}$ However, in most cases, lesions involute leaving telangiectasia, scars, excess skin or so-called fibrofatty residua. Extensive or ulcerated IHs with localizations impairing vital functions (such as periocular $\mathrm{IH}$ ), causing a significant cosmetic defect or directly threatening life with no access for surgical excision are an important clinical challenge, classified as inoperable. Attempted chemotherapeutic approaches have included, among other things, steroids or interferon $\alpha$, with unsatisfactory results. In 2008, a revolutionary successful pharmacological therapy was discovered: propranolol. ${ }^{3}$ Thanks to its rapid and spectacular results with minor side effects, propranolol is currently considered the first-line drug in the treatment of $\mathrm{IH}$.

Research is still being carried out to understand the exact mechanism of action of propranolol on $\mathrm{IH}$, to determine effective doses and the optimal algorithm of the therapy. Recently, the safe introduction of the drug in outpatient settings is being discussed. . $^{4,5}$

The aim of the study was to evaluate the safety of initiating and maintaining propranolol for $\mathrm{IH}$ in children based on cardiology and biochemical studies and the occurrence of adverse effects.

\section{Material and methods}

The analysis included 55 consecutive cases of infants with IH treated between 2011 and 2014. The criteria for inclusion were lesions that were inoperable, extensive, ulcerative, that impaired important vital functions, caused a significant cosmetic defect, or affected internal organs.

The Bioethics Committee at the Pomeranian Medical University (Szczecin, Poland) approved the study protocol and consent forms. Written informed consent was obtained from the legal guardians of all of the study participants and recorded in the patient files.

\section{Methods}

After taking patient histories regarding the coexistence of risk factors for $\mathrm{IH}$, the following clinical interventions were applied before treatment, during treatment and at the follow-up 1.5 months after treatment:

1. Physical examinations including assessments of the location, size, color, and consistency of the lesion.

2. Cardiac examinations including electrocardiography (ECG) and echocardiography with Doppler (ECHO), carried out by the same pediatric cardiologist, along with blood pressure (BP) and heart rate (HR) measurements.
3. Basic laboratory tests: blood count, ionogram, blood glucose concentration, aspartate transaminase (AST), and alanine transaminase (ALT).

4. The protocol of the initiation of propranolol, divided into 2 doses (at 8:00 am and 8:00 pm), was $0.5 \mathrm{mg} / \mathrm{kg} /$ day on day $1,1 \mathrm{mg} / \mathrm{kg} /$ day on day $2,1.5 \mathrm{mg} / \mathrm{kg} /$ day on day 3 , and $2.0 \mathrm{mg} / \mathrm{kg} /$ day on day 4 .

The treatment was carried out in the hospital for 4-5 days with HR, BP, saturation, and 4-fold blood glucose monitored over $24 \mathrm{~h}$; the treatment was then continued on an outpatient basis. The parents were taught to measure the pulse and glucose at home.

The therapy was continued until the child was at least 1-year old, when complete involution was observed or there was no further improvement. The drug was discontinued gradually, reducing the dosage over the next 1-3 months.

\section{Statistical analysis}

All continuous variables were checked for the normality of distribution using the Kolmogorov-Smirnov test. These variables were described as averages, medians, standard deviations, quartiles, and minimum and maximum values. The statistical differences between the 2 groups were tested with Student's t-test and the Mann-Whitney test. For multiple groups, multiple analysis of variation (MANOVA), analysis of covariance (ANCOVA) or the Kruskal-Wallis test were used. Discontinuous variables were described by the number and frequency of occurrence. Pearson's $X^{2}$ test was used for discontinuous variables. The statistical analysis was carried out using Stata v. 11 statistical software (StataCorp LLC, College Station, USA).

\section{Results}

Four children were excluded during the qualification or during the initiation of the therapy, for the following reasons: increased liver parameters (AST and ALT), worsening dyspnea symptoms due to laxity of the larynx, and arrhythmia in the form of bradycardia and paroxysmal tachycardia in 2 children. Extended cardiac diagnostics in these children did not show any abnormalities, but the parents did not agree to resume the treatment. A total of 51 patients were subject to the final analysis (Table 1). The corrected age at the time of initiating treatment in prematurely born children was after newborn age. Bronchopulmonary dysplasia observed in prematurely born children was not a contraindication for the inclusion in the study, as the patients with this conditions did not require pharmacological treatment.

The total number of IHs present in 51 patients was 79 . Infantile hemangiomas complicated with ulceration were found in 12 children (15\%).

All the children showed clinical improvement after the treatment. The detailed results were the subject of a previous publication. ${ }^{6}$ The best therapeutic effect was obtained 
in the group of the youngest children, who started the treatment up to the $6^{\text {th }}$ month of life. The final therapeutic effect in the form of complete atrophy of the IH was noted in $69 \%$ of the children in this group. In the 6-12-month-old children, complete involution was observed in 56\%, while among patients who started treatment after 1 year of age, complete involution was seen in $25 \%$.

\section{Cardiac examination}

The ECG examinations performed before, during and after the treatment were within the normal range.

The ECHO scans performed before the treatment was induced showed patent foramen ovales (PFOs) in 24 children and an atrial septal defect (ASD II) in 3 cases. In 1 child, the defect in the ASD coexisted with a perimembranous ventricular septal defect (VSD). The defects found in the ECHO scans were not contraindications for treatment with propranolol. In the control examinations after the full therapeutic dose was reached, a PFO was observed in 1 child, tricuspid regurgitation of the $1^{\text {st }}$ degree without hemodynamic significance in 1 case and accelerated flow in the pulmonary artery in 1 case. In the next examination performed during treatment (after 1 month), ASDs II were present in 2 children, VSDs in 1 and PFOs in 19 children. At the follow-up 1.5 months after treatment was ceased, there were ASDs II in 2 children, a VSD in 1 and PFOs in 5 children.

The HR was between $117 \mathrm{bpm}$ and $160 \mathrm{bpm}$ in all patients, while after switching to the full therapeutic dose, it dropped by $18 \mathrm{bpm}$ (98-136 bpm on average). The decrease in the HR after the full dose was reached was statistically
Table 1. Characteristics of the study group

\begin{tabular}{|l|c|}
\hline \multicolumn{1}{|c|}{ Characteristics } & Value \\
\hline Male, $\mathrm{n}[\%]$ & $15(29.4)$ \\
\hline Female, $\mathrm{n}[\%]$ & $36(70.6)$ \\
\hline Birth weight, range & $1,700-4,460$ \\
$<2,500 \mathrm{~g}, \mathrm{n}[\%]$ & $8(15.5)$ \\
$2,500-3,000 \mathrm{~g}, \mathrm{n}[\%]$ & $7(13.5)$ \\
$3,001-4,000 \mathrm{~g}, \mathrm{n}[\%]$ & $32(63)$ \\
$>4,000 \mathrm{~g}, \mathrm{n}[\%]$ & $4(8)$ \\
\hline Gestational age & \\
$<37 \mathrm{~W}, \mathrm{n}[\%]$, range [w] & $7(14), 32-36$ \\
$>=37 \mathrm{w}, \mathrm{n}[\%]$, range [w] & $44(86), 37-41$ \\
\hline Age at initiation of propranolol, average (range) & $5.8 \mathrm{~m}(7 \mathrm{w}-21.8 \mathrm{~m})$ \\
$7 \mathrm{w}-6 \mathrm{~m}, \mathrm{n}[\%]$ & $39(75)$ \\
$6-12 \mathrm{~m}, \mathrm{n}[\%]$ & $9(17)$ \\
$18.5-21.8 \mathrm{~m}, \mathrm{n}[\%]$ & $3(8)$ \\
Weight at initiation of propranolol, & \\
average (range) & \\
$<5,000 \mathrm{~g}, \mathrm{n}[\%]$ & $6(12)$ \\
$5,000-6,000 \mathrm{~g}$ & $16(31)$ \\
$6,001-7,000 \mathrm{~g}$ & $15(29.5)$ \\
$7,001-13,500 \mathrm{~g}$ & $14(27.5)$ \\
\hline
\end{tabular}

w-weeks; m - months.

significant in relation to the parameters before the treatment ( $\mathrm{p}=0.0001$ ) (Fig. 1). Further HR values in the ambulatory controls remained lower than the initial pretreatment parameters. However, in the maintenance period after 2 weeks of treatment, mean HR values increased in relation to the HR just after the full therapeutic dose was reached $(p=0.0039)$. Changes in mean HR values after discontinuation of the drug were not statistically significant, but showed a slight increase. During all the outpatient measurements,

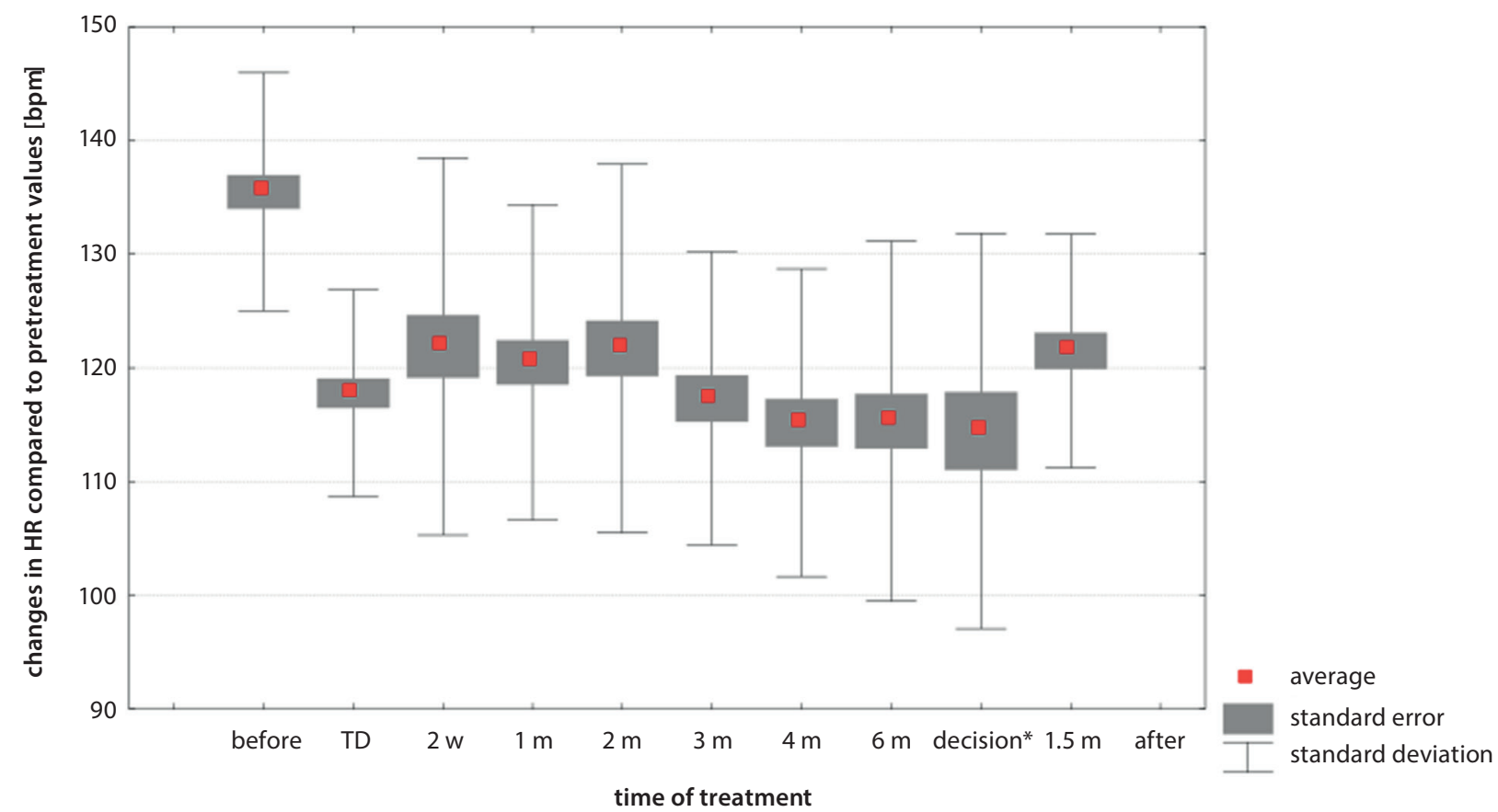

Fig. 1. Changes in the heart rate after induction of the full therapeutic dose and during subsequent outpatient monitoring

TD - therapeutic dose; HR - heart rate; *decision to gradually withdraw propranolol; w - weeks; $m$ - months. 
the mean HR parameters were normal in relation to age (114-122 bpm), with a minimum value of $80 \mathrm{bpm}$. One patient presented an episode of bradycardia during an ambulatory examination by a family doctor; this was not confirmed during a later cardiac check-up. Heart rate reference values were based on the recommendations of a group of European experts (Table 2). ${ }^{5}$

No hypotension was observed in any of the children before treatment $\left(\mathrm{BP}>5^{\text {th }}\right.$ percentile). Reference values were interpolated for age from 1 month to 1 year as follows: systolic blood pressure (SBP): P5 = $70 \mathrm{~mm} \mathrm{Hg}$, P90 = $105 \mathrm{~mm} \mathrm{Hg}$; diastolic blood pressure (DBP): P5 = $36 \mathrm{~mm} \mathrm{Hg}, \mathrm{P} 90=66 \mathrm{~mm} \mathrm{Hg}$.

Mean SBP was $103 \mathrm{~mm} \mathrm{Hg}$ (80-124 mm Hg), whereas after treatment with the full therapeutic dose it dropped by an average of $10 \mathrm{~mm} \mathrm{Hg}$ to a mean SBP of $93 \mathrm{~mm} \mathrm{Hg}$ (74-119 $\mathrm{mm} \mathrm{Hg}$ ). The mean SBP was significantly reduced relative to pretreatment parameters only after the full therapeutic dose was reached $(\mathrm{p}=0.00001)$ and in the first 3 months of treatment ( $p<0.039$ ) (Fig. 2). The average SBP during all outpatient monitoring was normal (92-102 $\mathrm{mm} \mathrm{Hg}$ ), reaching lower values in the first 3 months of treatment. After 4 months of treatment, a significant increase in the average SBP (by $7 \mathrm{~mm} \mathrm{Hg}$ ) was observed $(\mathrm{p}=0.0106)$. After the drug was discontinued, an increase in the mean SBP was noted, but it was not statistically significant in comparison to the results of the preceding check-up.

The parameters of the mean SBP were within normal limits, both before and after treatment. Values of SBP below the standard in individual measurements were sporadic (7 SBP measurements $(2 \%)$ were below the $5^{\text {th }}$ percentile) and were asymptomatic.
Table 2. Reference values for heart rate $(\mathrm{HR})$ and blood pressure $(\mathrm{BP})^{5,7}$

\begin{tabular}{|l|c|c|}
\hline \multicolumn{1}{|c|}{ Age [months] } & HR [bpm] & $\begin{array}{c}\text { BP (systolic/diastolic) } \\
{[\mathrm{mm} \mathrm{Hg}]}\end{array}$ \\
\hline $0-3$ & 100 & $65 / 45$ \\
\hline $3-6$ & 90 & $70 / 50$ \\
\hline $6-12$ & 80 & $80 / 55$ \\
$12-24$ & 70 & $80 / 55$ \\
\hline
\end{tabular}

Mean DBP was $61 \mathrm{~mm} \mathrm{Hg}$ (39-84 mm Hg), while after reaching the full therapeutic dose of the treatment, it decreased by an average of $8.7 \mathrm{~mm} \mathrm{Hg}$ to a mean DBP of $52.4 \mathrm{~mm} \mathrm{Hg}(40-72 \mathrm{~mm} \mathrm{Hg})$. The average DBP values were significantly reduced compared to pretreatment parameters only after the full therapeutic dose was reached $(p=0.00001)$ and during the first 3 months of treatment $(\mathrm{p}=0.0468)$ (Fig. 3). In the following months of treatment, a statistically significant increase in the average DBP (7.0-9.8 $\mathrm{mm} \mathrm{Hg}$ ) was observed in relation to the DBP after the therapeutic dose was reached $(\mathrm{p}<0.048)$. After the drug was discontinued, the changes observed in DBP were not significant compared to the results of the pre-withdrawal check-up.

The parameters of mean DBP were normal both before treatment, during outpatient monitoring and after completion of the therapy. Lower DBP values were observed sporadically (3 DBP measurements $(0.9 \%)$ were below the $5^{\text {th }}$ percentile) and were asymptomatic.

A detailed analysis of the results of $\mathrm{HR}$ and BP measurements during the gradual increase to the full therapeutic dose over 3-4 days during the patient's hospital stay is presented in Table 3. On average, each patient underwent

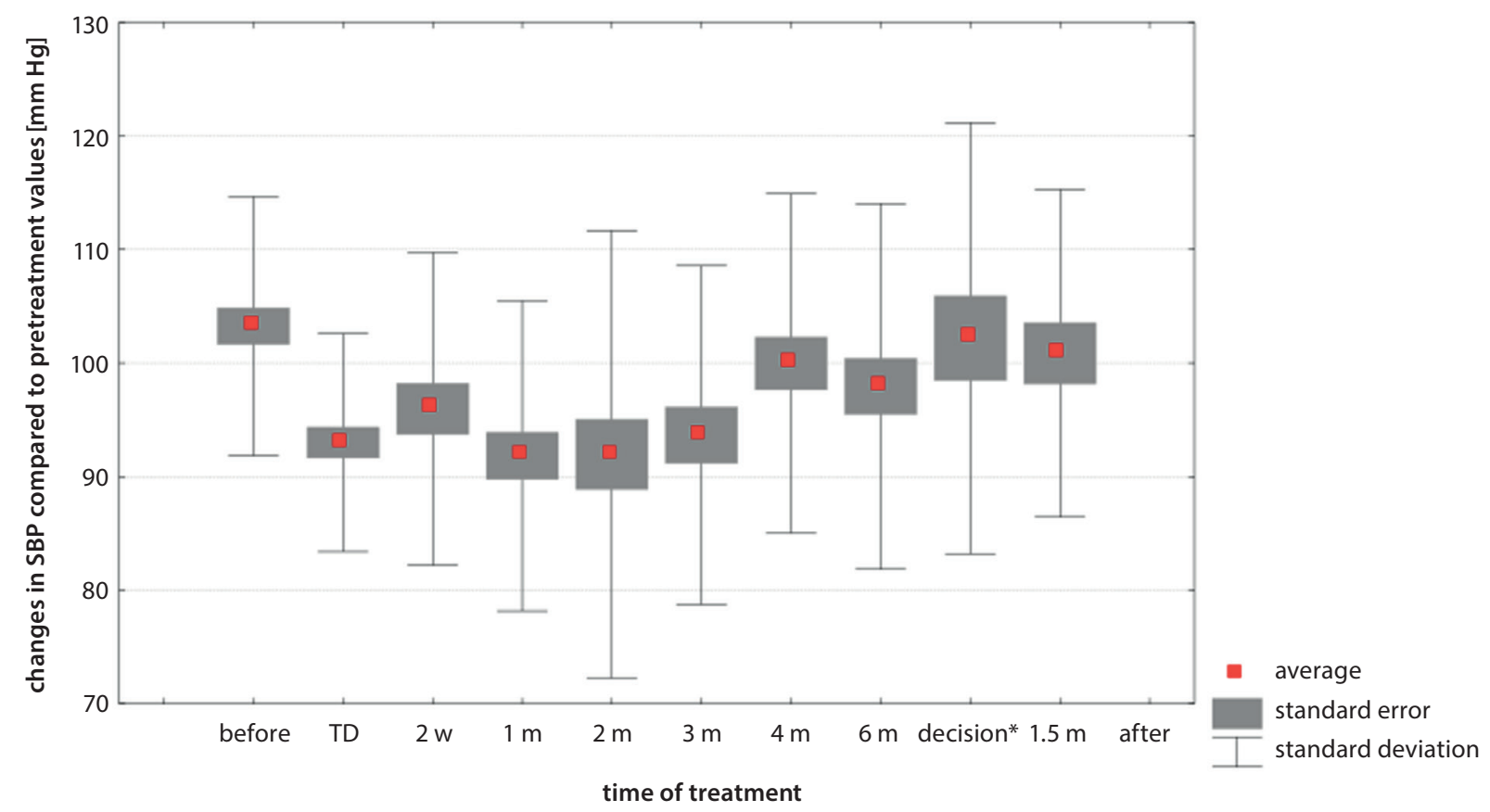

Fig. 2. Changes in systolic blood pressure after induction of the full therapeutic dose and during subsequent outpatient monitoring

TD - therapeutic dose; SBP - systolic blood pressure; *decision to gradually withdraw propranolol; $w$ - weeks; $m$ - months. 
5 measurements each day $(1 \mathrm{~h}, 2 \mathrm{~h}, 4 \mathrm{~h}, 6 \mathrm{~h}, 8 \mathrm{~h}$, and $10 \mathrm{~h}$ after the dose). In 17 children, the full therapeutic dose was reached on the $3^{\text {rd }}$ day of hospitalization.

The average HR values in all the children were within reference values. It was only on the $1^{\text {st }}$ day that the mean HR values were significantly different from those on other days $(\mathrm{p}<0.02)$. The mean HR values were significantly different in the youngest children $(1-3$ months of age $(\mathrm{p}<0.03)$ and $3-6$ months of age $(\mathrm{p}<0.009))$ (Fig. 4). The average minimum values of HR in the following days of treatment were also normal (112-105 bpm), with the lowest HR being a single measurement of $78 \mathrm{bpm}$. There were 6 episodes below the norm; bradycardia was therefore sporadic, as well as asymptomatic.

Minimal HR depended on the day of treatment; it was significantly lower on day 1 in relation to other days ( $p<0.0063)$. It did not depend on the age of the child.

The values of SBP and DBP before treatment (including mean SBP and DBP as well as minimal and maximal values) did not change during treatment days. There were no significant changes in any of the age groups analyzed. During the introduction of propranolol, no average SBP was below the $5^{\text {th }}$ percentile, whereas there was 1 average DBP below the $5^{\text {th }}$ percentile.

\section{Laboratory tests}

Slightly elevated AST values (max 77U/L with the laboratory reference $<32 \mathrm{U} / \mathrm{L}$ ) were present in 39 children; this was not a contraindication to proceeding with the therapy. During treatment, these values were reduced in 30 children, while they remained elevated in 9. After the end of the treatment, slightly elevated AST values $(\max 59 \mathrm{U} / \mathrm{L})$ were present in 32 patients. There was a mild elevation in ALT (by 3-14 U/L) in 10 children, but the results were still within the reference values $(<39 \mathrm{U} / \mathrm{L})$.

The mean serum glucose concentration was within the normal range before the treatment. Mean glycemia during the 4 days of the drug initiation phase was normal (97.3-98.8 $\mathrm{mg} / \mathrm{dL})$. In the study group, only 2 single

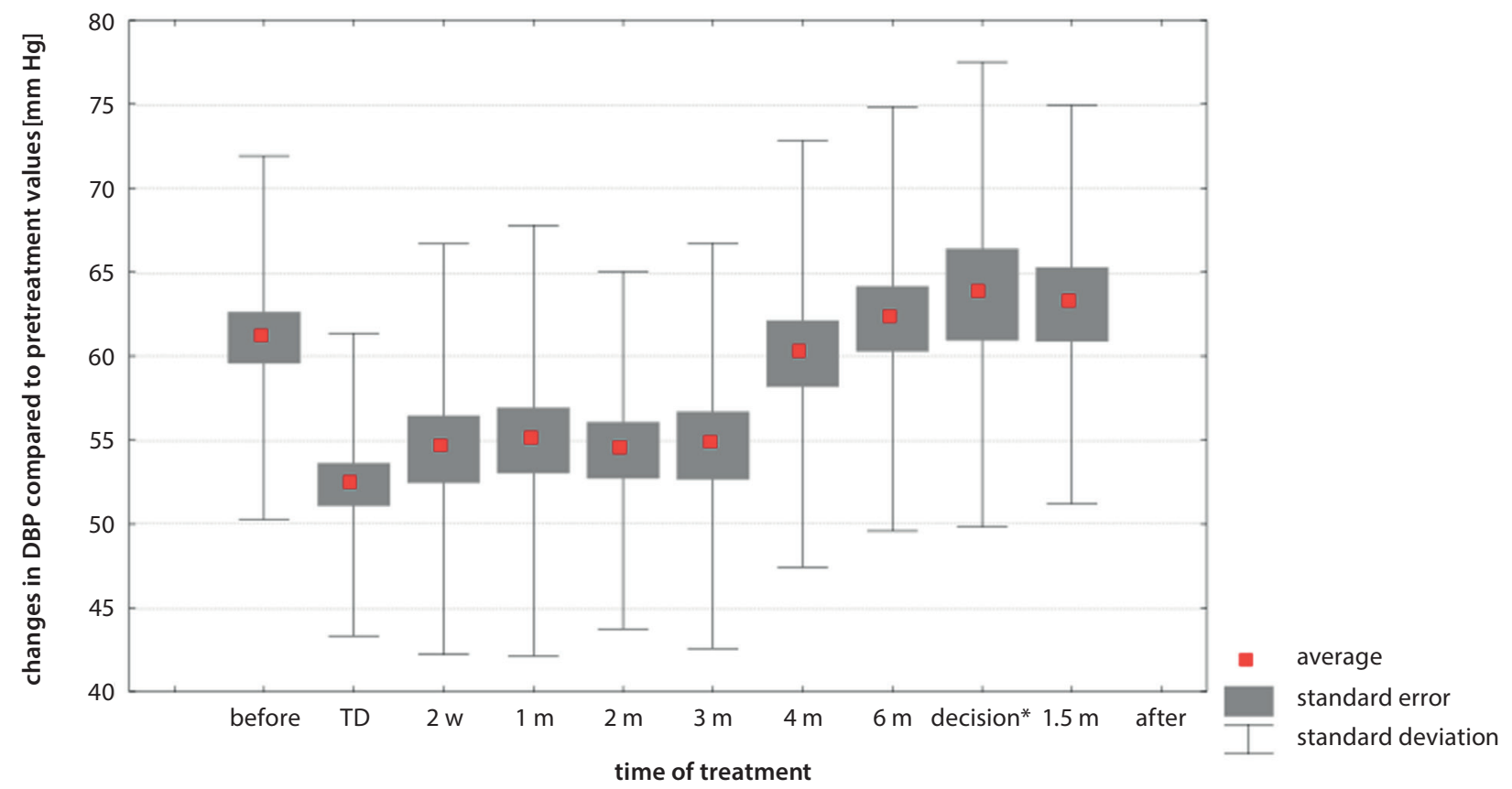

Fig. 3. Changes in diastolic blood pressure after induction of the full therapeutic dose and during subsequent outpatient monitoring

TD - therapeutic dose; DBP - diastolic blood pressure; *decision to gradually withdraw propranolo; $w$ - weeks; m - months.

Table 3. Analysis of the induction of propranolol therapy

\begin{tabular}{|l|c|c|c|c|c|c|c|c|}
$\begin{array}{c}\text { Day } \\
\text { of treatment }\end{array}$ & $\begin{array}{c}\text { Average dose } \\
{[\mathrm{mg} / \mathrm{kg} / \mathrm{day}]}\end{array}$ & $\begin{array}{c}\text { Decrease } \\
\text { in HR [bpm] }\end{array}$ & $\begin{array}{c}\text { Average HR } \\
\text { (range) [bpm] }\end{array}$ & $\begin{array}{c}\text { Episodes } \\
\text { of bradycardia (n) }\end{array}$ & $\begin{array}{c}\text { Decrease } \\
\text { in SBP }\end{array}$ & $\begin{array}{c}\text { Average SBP } \\
\text { (range) [mm Hg] }\end{array}$ & $\begin{array}{c}\text { Decrease } \\
\text { in DBP }\end{array}$ & $\begin{array}{c}\text { Average DBP } \\
(\mathbf{r a n g e})[\mathrm{mm} \mathrm{Hg}]\end{array}$ \\
\hline 1 & $0.56 \pm 0.24$ & 7.2 & $128.4(93.5-150.3)$ & 1 & 4.4 & $97.9(75.3-131.7)$ & 8.2 & $53.4(36.0-76.0)$ \\
\hline 2 & $1.13 \pm 0.24$ & 11 & $124.6(104.8-142.8)$ & 0 & 4.9 & $97.4(74.3-124.8)$ & 8.7 & $52.9(33.0-77.3)$ \\
\hline 3 & $1.64 \pm 0.22$ & 14 & $121.6(100.5-136.4)$ & 4 & 5 & $97.3(77.0-116.3)$ & 7.9 & $53.7(37.0-72.0)$ \\
\hline 4 & $1.93 \pm 0.14$ & 15.6 & $120.1(100.2-135.4)$ & 1 & 5.4 & $96.1(76.8-115.0)$ & 13.4 & $50.3(36.5-68.8)$ \\
\hline
\end{tabular}

$\mathrm{HR}$ - heart rate; SBP - systolic blood pressure; DBP - diastolic blood pressure. 


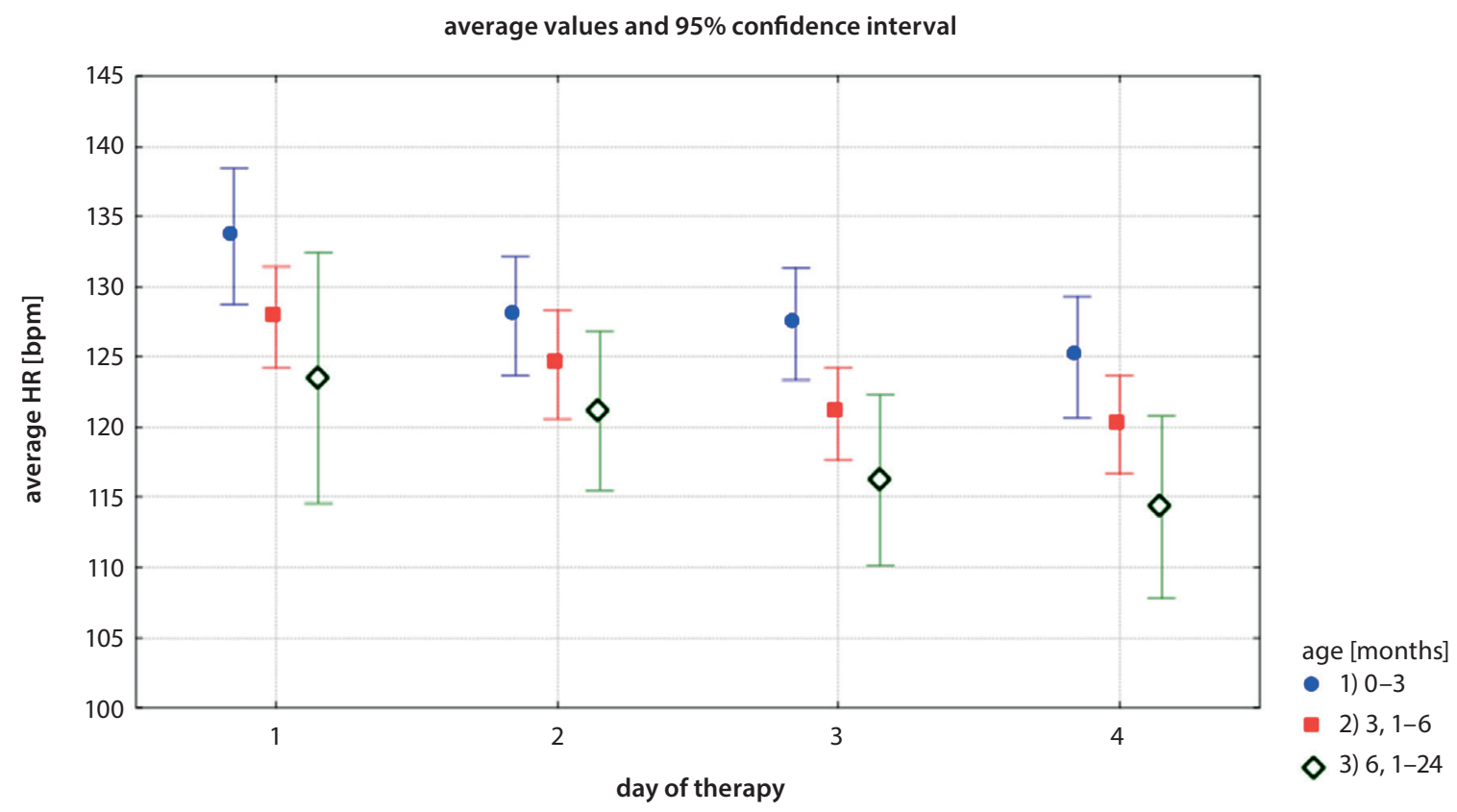

Fig. 4. Average values of heart rate (HR) during the induction of propranolol therapy, with divisions into age groups

measurements had below-standard glycemia $<60 \mathrm{mg} / \mathrm{dL}$ : $56 \mathrm{mg} / \mathrm{dL}$ in a child younger than 3 months on the $2^{\text {nd }}$ day and $58 \mathrm{mg} / \mathrm{dL}$ in a child 3-6-month old on the $4^{\text {th }}$ day. No outbreaks of hypoglycemia were observed during outpatient monitoring. In 3 patients, episodes of asymptomatic hypoglycemia (41-50 mg/dL) were observed during parental home measurements. One child had symptomatic hypoglycemia of $44 \mathrm{mg} / \mathrm{dL}$, manifested by sweating, drowsiness, apathy, and vomiting and requiring hospitalization in the $2^{\text {nd }}$ week of treatment. These symptoms resolved after a dose reduction.

No ion abnormalities were detected in any of the children.

\section{Evaluation of the treatment proceedings}

\section{Drug dosage}

The target therapeutic dose was $2 \mathrm{mg} / \mathrm{kg} /$ day $(1.3-2.2 \mathrm{mg} /$ $\mathrm{kg} /$ day) divided into 2 daily doses. In 6 children, the therapy started with a lower dose (1.3-1.6 mg/ $/ \mathrm{kg} /$ day) due to younger age, low body weight and low serum glucose levels, as well as lower BP and HR values. Moreover, extensive skin changes associated with atopic dermatitis and the risk of developing asthmatic symptoms were also reasons for lowering the initial dose. In 5 of these children, the dose was increased to the target dose after 1 month without side effects. In addition, 6 other children required a therapeutic dose reduction to $0.9-1.6 \mathrm{mg} / \mathrm{kg} /$ day due to adverse reactions (frequent spitting and vomiting, sleep disturbances, frequent respiratory infections, symptomatic hypoglycemia, reflux, and suspected bronchial asthma). In 4 of these children, the dose reduction resulted in a slightly worse final effect.

\section{Treatment period}

The full therapeutic dose period was on average 8.7 months; in the cases of periocular lesions, it was 11.4 months. The total length of treatment, including the gradual withdrawal of the drug (1.5-3 months), was 12 months on average.

\section{Adverse effects}

Mild adverse reactions occurred in 17 (33\%) children. In this group, single episodes of asymptomatic hypoglycemia (41-50 mg\%) were observed in 3 patients, symptomatic hypoglycemia ( $44 \mathrm{mg} \%$ ) in 1 patient and sleep disorders in 2 children. Frequent respiratory infections were noted in 3 cases, bradycardia in 1 child, worse body weight gain in 4 children and excessive drowsiness in 1 child. Constipation was observed in 1 patient. In 2 children, it was necessary to perform additional diagnostics for asthma; in 1 of these children, the diagnosis was extended to gastroesophageal reflux.

\section{Discussion}

The development of $\mathrm{IH}$ is a long process. It is considered that about $30 \%$ of untreated lesions involute within a child's first 3 years of life and 50\% within 5 years. ${ }^{8}$ Accordingly, in about 2 years of observation, $\mathrm{IH}$ should disappear in $20 \%$ of patients. ${ }^{9}$ In the study group, a 3 -fold higher rate of hemangioma atrophy was achieved within 8.7 months of treatment with propranolol. This indicates that propranolol contributes significantly to the involution of $\mathrm{IH}$. 
It is worth emphasizing that the early introduction of propranolol treatment slows down the phase of intensive IH growth, which reduces the risk of cosmetic defects and the need for complementary treatment such as excision or laser therapy. ${ }^{4}$ This is supported by the fact that the best results in our study were observed among the patients that were the youngest at the induction of propranolol. This justifies the importance of research on the safety of propranolol, especially for the youngest patients, who are potentially the main beneficiaries of the therapy.

Hengst et al. were the first to present the results of BP, HR and glucose monitoring in 109 children at the average age of 2.8 months during the induction of propranolol in hospital setting. ${ }^{7}$ In 3-4 days, the dose was gradually increased from $0.5 \mathrm{mg} / \mathrm{kg} /$ day to $2 \mathrm{mg} / \mathrm{kg} /$ day. They continued the assessment up to 6 months. However, in contrast to our study, they excluded prematurely born children and those with confirmed heart defects from the study. They observed no hypotension after 3 months of treatment. No clinical signs of hypotension, bradycardia or other adverse events were present. As in our study, HR and laboratory parameters were normal. The authors concluded that in healthy infants, $2 \mathrm{mg} / \mathrm{kg} /$ day of propranolol divided into 3 doses is well tolerated and that monitoring of BP during longterm treatment is not necessary. ${ }^{7}$

Puttgen et al. also assessed HR, BP and glycemia during the initiation of propranolol treatment. ${ }^{10}$ In a study of over 50 patients at a median age of 3.4 months, the treatment was started at a dose of $1 \mathrm{mg} / \mathrm{kg} /$ day; on day 2 it was increased to $2 \mathrm{mg} / \mathrm{kg} /$ day. All the patients had at least 1 low SBP or DBP, 2/3 (76\%) had at least 1 measurement of both low SBP and low DBP, and 14\% of the children had an episode of bradycardia. Despite the high incidence of these deviations, they were asymptomatic and did not affect the therapeutic dose. They also showed that children over the age of 6 months presented bradycardia more often than younger infants $(\mathrm{p}<0.001)$. Mean SBP, DBP and HR were significantly reduced between day 1 and day $2(\mathrm{p}=0.004)$ but did not change from day 2 to day $3 .^{10}$ In our study, only a decrease in HR was observed between the $1^{\text {st }}$ day of therapy and the remaining days.

In 31 children at the average age of 4.6 months, Liu et al. observed a decrease in SBP during the induction phase by $4 \mathrm{~mm} \mathrm{Hg}$, without statistically significant changes in DBP or glycemia. ${ }^{11}$ The drug was introduced immediately in the full therapeutic dose of $2 \mathrm{mg} / \mathrm{kg} /$ day divided into 3 doses, without a gradual increase. The study suggests that a 24-hour hospitalization with monitoring may not be necessary for otherwise healthy infants. ${ }^{11}$

Hypotension is most frequently observed in the first $2 \mathrm{~h}$ after administration of the drug. ${ }^{12}$ A low incidence of asymptomatic systolic hypotension during the induction phase was observed by Hermans et al. ${ }^{13}$ However, the study group was heterogeneous, with a high proportion of premature babies (22.4\%); the dose ranged from $1 \mathrm{mg} / \mathrm{kg} /$ day to $3 \mathrm{mg} / \mathrm{kg} / \mathrm{day}$; and some children were administered steroids. ${ }^{13}$ However, in a study by Filippi et al., 19.2\% of premature babies treated with propranolol at doses of $1-2 \mathrm{mg} / \mathrm{kg} /$ day developed symptomatic hypotonia, bradycardia or both. ${ }^{14}$ Marqueling et al. published a large meta-analysis of 41 reports on 1,264 children (mean age 6.6 months, dose $2.1 \mathrm{mg} / \mathrm{kg} /$ day, therapy time 6.4 months), recording BP decreases in 39 children (3\%), in 5 of whom $(0.4 \%)$ it was symptomatic. ${ }^{15}$ In the study group, hypotension was asymptomatic and occurred sporadically during both the initiation and maintenance periods. However, on the $2^{\text {nd }}$ day of the therapy, bradycardia and hypotension were the reasons for discontinuing the drug in 1 child. Another patient was disqualified due to tachycardia.

In our study, a significant reduction in HR was observed during the induction of therapy in comparison to the values before the treatment. The average HR values during the gradual increase in the dosage were all within the normal range. The average HR value on the $1^{\text {st }}$ day were significantly different from the values on the following days; this was the only statistically significant difference in HR values. The reported cases of bradycardia were sporadic and asymptomatic, as in reports by other authors. ${ }^{10,11}$ The average SBP and DBP values did not change over time and did not significantly differ during the subsequent days of therapy. There was no decrease in SBP below the $5^{\text {th }}$ percentile, and in the case of mean DBP, such a decrease was recorded only once. These results demonstrate a high level of safety in the introduction of propranolol.

Bradycardia is usually observed in the first $1-3 \mathrm{~h}$ of drug administration. ${ }^{4}$ Therefore, observation for such a period of time may be sufficient in outpatient conditions. In the study group, asymptomatic bradycardia was observed in only 1 child in the $1^{\text {st }}$ month of treatment, immediately after administration of the drug. Bradycardia was not registered either in the next Holter examination or during outpatient supervision.

Blood pressure was not monitored outside the induction phase in any of the abovementioned studies except Hengst et al., whose results suggest that BP screening should be performed only in the initial phase of treatment. ${ }^{7}$ European and American expert groups recommend monitoring $\mathrm{BP}$ in healthy infants only when starting treatment with propranolol and increasing its dose by $>0.5 \mathrm{mg} / \mathrm{kg} /$ day. ${ }^{4,5,7}$

Our observations show that continuing treatment at a dose of $2 \mathrm{mg} / \mathrm{kg} /$ day is safe. The reduction in $\mathrm{HR}$ observed after induction was compensated after 2 weeks, as a result of possible drug tolerance rather than as a result of a relative reduction in the dose as children gained weight. Therefore, it would be reasonable to introduce the drug in ambulatory conditions. Moreover, a few days long break between dosage increases can ensure the safety of the process. The statistically significant decrease in mean SBP and DBP values observed in the first 3 months of our study still remained within the normal range. The hypotensive episodes observed were rare and asymptomatic. This indicates a high degree of safety of propranolol therapy. 
In the past, ECGs, ECHO scans and consultations with pediatric cardiologists before, during and after propranolol treatment were obligatory. ${ }^{16,17}$ Some authors, however, question the need for ECHO before starting treatment. ${ }^{4,18}$ Liu et al. recommend performing this test in cases of a heart murmur or a positive interview. ${ }^{11}$ Blei et al. analyzed the results of 239 children under 1 year evaluated by a cardiologist before treatment with propranolol. ${ }^{19}$ In $21 \%$ of the children, ECHO heart abnormalities were found, but as in our study, the ECHO findings were not a contraindication for propranolol therapy. Cardiac contraindications for propranolol are rare (congestive heart failure with myocarditis, second- and third-degree heart block with bradycardia, and hypotension), but cardiac anomalies are more common in the $\mathrm{IH}$ population than in the healthy population. ${ }^{19}$ At present, the recommended approach is to perform ECG and cardiac consultations in cases of a positive medical history or arrhythmia. ${ }^{5}$ Routine ECHO scans are not necessary, except for specific clinical indications, since all other circulatory disorders that are contraindications to propranolol treatment can be assessed during the physical examination and history taking. ${ }^{5}$ Recent pharmacokinetic studies showed that propranolol reaches its balance in newborns after $48 \mathrm{~h} .{ }^{14}$ A retrospective analysis of 24-hour Holter exams conducted $48 \mathrm{~h}$ after the $1^{\text {st }}$ dose of propranolol did not reveal any persistent arrhythmias. ${ }^{20}$

Pretreatment laboratory tests allow us to detect possible value disturbances before therapy. Numerous studies have confirmed the low usability of these tests in monitoring treatment due to the low frequency of disturbances, for example hyperkalemia. ${ }^{21}$ There are also no indications for routine serum glucose screening during the course of propranolol therapy due to the varied and unpredictable time of occurrence of hypoglycemic episodes. The indications for blood glucose is prematurity or hypertrophy, with growth disorders and hypoglycemia. ${ }^{5}$

The first recommendations of propranolol treatment for IH were published in 2013. ${ }^{4}$ Hospital treatment was indicated for infants under 8 weeks of corrected age and in the absence of adequate social support, the occurrence of a concomitant pathology of the heart and/or lungs, and glycemic disorders. According to the 2015 recommendations of European experts, the introduction of the drug takes place in a hospital setting. ${ }^{5}$ This strictly applies to children under 8 weeks of age, children with a body weight $<3.5 \mathrm{~kg}$, premature babies (because the risk of bradycardia and low BP in premature babies is high), children with life-threatening hemangiomas, PHACE syndrome and coexisting cardiovascular and respiratory diseases, impaired glycemic levels, and those with insufficient care in the home environment. ${ }^{4,14}$ Older infants can be hospitalized for part of a 1-day stay. Treatment of older children or a resumption of propranolol treatment can be started on an outpatient basis, with a gradual dosage increase once a week, starting with a dose of $1 \mathrm{mg} / \mathrm{kg} /$ day, and ending with a dose of 2 (or 3 ) $\mathrm{mg} / \mathrm{kg} / \mathrm{day}$, with BP and HR monitoring before each dose increase and $1 \mathrm{~h}$ or $2 \mathrm{~h}$ after administration.

The aforementioned group of European experts stated that the therapeutic dose should be in the range of $2 \mathrm{mg} / \mathrm{kg} /$ day to $3 \mathrm{mg} / \mathrm{kg} /$ day, administered in 2 or 3 doses. ${ }^{5}$ If propranolol is administered in 2 doses, the average serum concentrations of the drug are about $12 \%$ higher than with 3 doses per day. ${ }^{4}$ In our study group, the treatment was started from $0.5 \mathrm{mg} / \mathrm{kg} /$ day and gradually increased to $2 \mathrm{mg} / \mathrm{kg} /$ day divided into 2 doses, with high clinical effectiveness.

Adverse effects during propranolol therapy are extremely rare. Transient hypoglycemia is observed in $0.9-11.4 \%$ of patients. ${ }^{4}$ Inhibition of glycogenolysis, gluconeogenesis and lipolysis by propranolol is considered the most likely cause. Preterm children are particularly predisposed. In our study, asymptomatic hypoglycemia (41-50 mg/dL) in the monitoring performed by parents at home occurred in 1 preterm child and 2 other children. Early initiation of treatment in 1 patient (at 7 weeks of age) and co-infection in the others were regarded as the probable causes. Hypoglycemia has been reported in various periods of propranolol treatment, regardless of age. The condition is probably caused by overly long interruptions in feeding or by coinfection. ${ }^{4}$ Therefore, parent education in the diagnosis of hypoglycemic symptoms, the importance of frequent feeding, avoiding long breaks between meals, administration of the drug with a meal, and special care in cases of overlapping infections, local infections, vomiting, and/or diarrhea seems to be sufficient, and glucose testing in the treated children seems unnecessary. According to Drolet et al., special care should be taken when introducing treatment before the $8^{\text {th }}$ week of age. ${ }^{4}$ A typical symptom of hypoglycemia is tachycardia, which can be masked by propranolol. Therefore, attention should be paid to other symptoms, such as sweating, drowsiness, loss of appetite, seizures, apneas, fainting, and hypothermia, which may also indicate low blood sugar levels. Fusilli et al. recorded the lowest value of glycemia $(15 \mathrm{mg} / \mathrm{dL})$ in a 6-month-old boy during therapy, and convulsions were the first symptom observed. ${ }^{22}$ Only a few cases of symptomatic hypoglycemia have been described. ${ }^{22-25}$ In our study group, symptomatic transient hypoglycemia was observed in 1 patient in the $2^{\text {nd }}$ week of treatment, accompanied by excessive sleepiness, pallor and loss of appetite, which resolved after reducing the daily dose of the drug during hospitalization. It was a unique case report. Perhaps the reason for the hypoglycemia in that child was a coexisting local infection of an ulcerated hemangioma. Accidentally detected episodes of hypoglycemia observed at home were sporadic and were seen in the youngest participants, those prematurely born or with comorbid infections. Our results suggest that performing frequent glycemic measurements during the introduction of propranolol may be unnecessary, which concurs with other authors. ${ }^{4,5}$ 
Drolet et al. emphasized the possibility of sporadic occurrences of other transient adverse effects, such as bradycardia (0.9-8.7\%), respiratory tract infections (1.4-8\%), sleep disturbances (3.7-13.5\%), low blood pressure (3.1-21\%), and gastroesophageal reflux (0.7-6\%). Asthma and allergic conditions are contraindications to the use of propranolol, which, as a non-selective inhibitor of $\beta$-adrenergic receptors, can cause bronchospasm. The appearance of wheezing or shortness of breath without the symptoms of infection is an indication for discontinuation of propranolol therapy.

Symptoms of the central nervous system in the form of sleep disorders or excessive irritability probably result from the easy penetration of the drug into the nervous system. ${ }^{4}$ Propranolol is very lipophilic, which in theory may be associated with adverse effects on neurological or cognitive development. ${ }^{5,26}$ The sleep disorders and anxiety observed in 2 of our patients resolved after treatment.

The necessity of discontinuing propranolol treatment due to complications is extremely rare. Only single cases of discontinuing therapy due to life-threatening symptoms are described in the literature. The most frequently mentioned are persistent bradycardia, bronchospasm in the course of respiratory tract infections, asthma, and sudden drops in blood pressure. ${ }^{27-30}$

The fairly high percentage of mild and transient adverse reactions observed in our study (18\%) is consistent with the observations of other authors reporting on large groups of patients. ${ }^{31,32}$ Adverse events in long-term ambulatory monitoring should be reported.

Propranolol is an effective and safe drug, which leads to involution of $\mathrm{IH}$ in a short time. The numerous benefits and safety of propranolol have been demonstrated in studies involving a large number of patients ${ }^{13,15,33}$ and 2 randomized trials. ${ }^{34,35}$ Our results indicate a strong basis for shifting propranolol therapy to outpatient settings.

\section{Conclusions}

Propranolol is effective, safe and well-tolerated by children with infantile hemangiomas. The positive results of the safety assessment in hospital conditions support the strategy of initiating and maintaining propranolol therapy in the outpatient setting in children with IH. Future studies are needed to assess the benefits of introducing the therapy in the outpatient setting.

\section{ORCID iDs}

Lidia Babiak-Choroszczak (D) https://orcid.org/0000-0002-6808-5894 Kaja Giżewska-Kacprzak (D) https://orcid.org/0000-0002-5870-9464 Grażyna Dawid (D) https://orcid.org/0000-0002-1505-7806 Elżbieta Gawrych (D) https://orcid.org/0000-0002-6050-4046 Maciej Bagłaj (D) https://orcid.org/0000-0001-9848-7889

\section{References}

1. Janmohamed SR, de Waard-van der Spek FB, Madern GC, de Laat PC, Hop WC, Oranje AP. Scoring the proliferative activity of haemangioma of infancy: The Haemangioma Activity Score (HAS). Clin Exp Dermatol. 2011;36(7):715-723.

2. Finn MC, Glowacki J, Mulliken JB. Congenital vascular lesions: Clinical application of a new classification. J Pediatr Surg. 1983;18(6):894-900.

3. Léauté-Labrèze $C$, Dumas de la Roque $E$, Hubiche T, Boralevi F, Thambo JB, Taïeb A. Propranolol for severe hemangiomas of infancy. NEngl J Med. 2008;358(24):26492651.

4. Drolet BA, Frommelt PC, Chamlin SL, et al. Initiation and use of propranolol for infantile hemangioma: Report of a consensus conference. Pediatrics. 2013;131(1):128-140.

5. Hoeger PH, Harper Jl, Baselga E, et al. Treatment of infantile haemangiomas: Recommendation of a European expert group. Eur J Pediatr. 2015;174(7):855-865

6. Babiak-Choroszczak L, Giżewska-Kacprzak K, Gawrych E, et al. Serum concentrations of VEGF and bFGF in the course of propranolol therapy of infantile hemangioma in children: Are we closer to understand the mechanism of action of propranolol on hemangiomas? Adv Clin Exp Med. 2018;27(5):703-710.

7. Hengst $\mathrm{M}$, Oelert $\mathrm{M}$, Hoeger $\mathrm{PH}$. Blood pressure monitoring during the induction and maintenance period of propranolol therapy for complicated infantile hemangiomas: A prospective study of 109 infants. Pediatr Dermatol. 2015;32(6):802-807.

8. Wyrzykowski D, Bukowski M, Jaśkiewicz J. Guzy naczyniowe i wrodzone malformacje naczyniowe. Cancer Surgery. 2009;1(1):1-17.

9. Rajewska J, Gawrych E, Fischer K, Walecka A, Brzosko M, Kwas A. Estimation of vascular endothelial growth factor and placental growth factor serum levels' in infant with hemangioma and population of healthy infants. Ann Acad Med Stetin. 2012;58(2):5-10.

10. Puttgen KB, Summerer B, Schneider J, Cohen BA, Boss EF, Bauman NM. Cardiovascular and blood glucose parameters in infants during propranolol initiation for treatment of symptomatic infantile hemangiomas. Ann Otol Rhinol Laryngol. 2013;122(9):550-554.

11. Liu LS, Sokoloff D, Antaya RJ. Twenty-four-hour hospitalization for patients initiating systemic propranolol therapy for infantile hemangiomas: Is it indicated? Pediatr Dermatol. 2013;30(5):554-560.

12. Cushing SL, Boucek RJ, Manning SC, Sidbury R, Perkins JA. Initial experience with a multidisciplinary strategy for initiation of propranolol therapy for infantile hemangiomas. Otolaryngol Head Neck Surg. 2011;144(1):78-84.

13. Hermans DJ, Bauland CG, Zweegers J, van Beynum IM, van der Vleuten CJ. Propranolol in a case series of 174 patients with complicated infantile haemangioma: Indications, safety and future directions. Br J Dermatol. 2013;168(4):837-843.

14. Filippi L, Cavallaro G, Fiorini P. Propranolol concentrations after oral administration in term and preterm neonates. J Matern Fetal Neonatal Med. 2013;26(8):833-840.

15. Marqueling AL, Oza V, Frieden IJ, Puttgen KB. Propranolol and infantile hemangiomas four years later: A systematic review. Pediatr Dermatol. 2013;30(2):182-191.

16. Lawley LP, Siegfried E, Todd JL. Propranolol treatment for hemangioma of infancy: Risks and recommendations. Pediatr Dermatol. 2009;26(5):610-614.

17. Przewratil P, Sitkiewicz A, Kierzkowska B, Lewandowska M, Lewandowska M, Andrzejewska E. Doświadczenia własne w leczeniu propranololem naczyniaków wczesnodziecięcych - doniesienie wstępne. Med Wieku Rozwoj. 2011;15:406-413.

18. You HS, Kim HS, Kim BS, Kim MB, Ko HC. Propranolol to treat infantile hemangioma $(\mathrm{IH})$ in patients with congenital heart disease. J Am Acad Dermatol. 2015;72(5):912-914.

19. Blei F, McElhinney DB, Guarini A, Presti S. Cardiac screening in infants with infantile hemangiomas before propranolol treatment. Pediatr Dermatol. 2014;31(4):465-470.

20. Jacks SK, Kertesz NJ, Witman PM, Fernandez Faith E. Experience with Holter monitoring during propranolol therapy for infantile hemangiomas. J Am Acad Dermatol. 2015;73(2):255-257.

21. Pavlakovic H, Kietz S, Lauerer P, Zutt M, Lakomek M. Hyperkalemia complicating propranolol treatment of an infantile hemangioma. Pediatrics. 2010;126(6):e1589-1593. 
22. Fusilli G, Merico G, Gurrado R, Rosa T, Acquafredda A, Cavallo L. Propranolol for infantile haemangiomas and neuroglycopenic seizures. Acta Paediatr. 2010;99(12):1756.

23. Holland KE, Frieden IJ, Frommelt PC, Mancini AJ, Wyatt D, Drolet BA. Hypoglycemia in children taking propranolol for the treatment of infantile hemangioma. Arch Dermatol. 2010;146(7):775-778.

24. Bonifazi E, Acquafredda A, Milano A, Montagna O, Laforgia N. Severe hypoglycemia during successful treatment of diffuse hemangiomatosis with propranolol. Pediatr Dermatol. 2010;27(2):195-196.

25. Breur JM, de Graaf M, Breugem CC, Pasmans SG. Hypoglycemia as a result of propranolol during treatment of infantile hemangioma: A case report. Pediatr Dermatol. 2011;28(2):169-171.

26. Langley A, Pope B. Propranolol and central nervous system function: Potential implications for pediatric patients with infantile hemangiomas. Br J Dermatol. 2015;172(1):13-23.

27. Vassallo P, Forte R, Di Mezza A, Magli A. Treatment of infantile capillary hemangioma of the eyelid with systemic propranolol. Am JOphthalmol. 2013;155(1):165-170.

28. Thoumazet F, Léauté-Labrèze $C$, Colin J. Mortemousque B. Efficacy of systemic propranolol for severe infantile haemangioma of the orbit and eyelid: A case study of eight patients. Br J Ophthalmol. 2012;96(3):370-374.
29. Claerhout I, Buijsrogge M, Delbeke P, et al. The use of propranolol in the treatment of periocular infantile haemangiomas: A review. Br J Ophthalmol. 2011;95:1199-1202.

30. Missoi TG, Lueder GT, Gilbertson K, Bayliss SJ. Oral propranolol for treatment of periocular infantile hemangiomas. Arch Ophthalmol. 2011;129(7):899-903.

31. Menezes MD, McCarter R, Greene EA, Bauman NM. Status of propranolol for treatment of infantile hemangioma and description of a randomized clinical trial. Ann Otol Rhinol Laryngol. 2011;120(10):686-695.

32. Patel NJ, Bauman NM. How should propranolol be initiated for infantile hemangiomas: Inpatient versus outpatient? Laryngoscope. 2014; 124(6):1279-1281

33. Léaute-Labrèze $C$, Boccara $O$, Degrugillier-Chopinet $C$, et al. Safety of oral propranolol for the treatment of infantile hemangioma: A systematic review. Pediatrics. 2016;138(4):e20160353.

34. Léauté-Labrèze $C$, Hoeger $P$, Mazereeuw-Hautier J, et al. A randomized, controlled trial of oral propranolol in infantile hemangioma. N Engl J Med. 2015;372(8):735-746.

35. Hogeling M, Adams S, Wargon O. A randomized controlled trial of propranolol for infantile hemangiomas. Pediatrics. 2011;128(2):e259-266. 